\title{
Colonos, índios e negros na fronteira do Cabo Norte (1700-1750)
}

\author{
Settlers, Indians and Blacks in the \\ Border of the Cabo Norte (1700-1750)
}

Rafael Ale Rocha *,

\section{Resumo}

$\mathrm{O}$ presente artigo pretende analisar o território chamado Cabo Norte (Amapá), durante as primeiras décadas do século XVIII, enquanto espaço que agregava diversificados indivíduos e/ou grupos sociais (índios, negros, mestiços, colonos franceses e portugueses, autoridades e missionários) e interesses imperiais - especialmente os das coroas de Portugal e França. Com base em correspondências trocadas entre autoridades diversas, observa-se que os grupos mencionados condicionavam a situação fronteiriça, e por ela eram condicionados, para satisfazer os respectivos interesses e elaborar suas políticas de atuação. Da mesma forma, enquanto objeto especial de nossa atenção, o faziam os variados grupos indígenas que ali habitavam, principalmente os aruãs.

Palavras-chave: Amazônia colonial; fronteiras coloniais; Cabo Norte; políticas indígenas.

\section{Abstract}

This article analyzes the territory called Cabo Norte (Amapá) during the first decades of the 18th century, as a space that included diverse individuals and social groups (Indians, blacks, mestizos, French and Portuguese settlers, authorities, and missionaries) and imperial interests - especially those of the crowns of Portugal and France. Based on diverse correspondences, we will observe that the mentioned groups conditioned the frontier situation and were conditioned by it, to satisfy their respective interests and elaborate their policies of action. In the same way, a special object of our attention are the various indigenous groups that inhabited it, principally, the aruãs.

Keywords: colonial Amazon; colonial frontiers; Cabo Norte; indigenous policies.

\footnotetext{
*Universidade do Estado do Amazonas (UEA), Manaus, AM, Brasil. rafael_ale_rocha@yahoo.com.br $<$ https://orcid.org/0000-0002-3516-5783>
} 
Entre fins do século XVII e início do XVIII, Portugal e França iniciaram negociações para solucionar, pela via diplomática, conflitos decorrentes da disputa entre as partes, agravados a partir da década de 1680 pela posse da região conhecida como Cabo Norte (Amapá). Grosso modo, os debates, que envolveram embaixadores e diplomatas de ambas as coroas, disputavam a foz do rio Amazonas e se valiam dos antecedentes históricos para provar, a favor de seus respectivos impérios coloniais, a pioneira presença e ocupação efetiva da região contestada. Em síntese, as negociações resultaram nos tratados de 1700, 1701 e 1713. Os dois primeiros consolidaram o Cabo Norte como área neutra. O último, assinado na cidade de Utrecht, cedia de uma vez por todas o território em disputa ao império português e, definindo o rio Oiapoque ou Vicente Pinzon como o limite entre as partes, proibia o trânsito entre o Estado do Maranhão e Grão-Pará (grosso modo, a Amazônia Portuguesa) e Caiena e o estabelecimento de relações comerciais transfronteiriças ${ }^{2}$ entre os dois espaços (Reis, 1993, p. 102-118). Durante os debates que resultaram no tratado de 1700, em um memorial que visava responder a uma réplica de um embaixador francês, o conselheiro português Roque Monteiro Paim apresentou o que, a nosso ver, veio a ser a base das argumentações lusitanas nessa e em outras contendas de mesma natureza: a necessidade de consolidar o 'domínio' Estados, capitanias, entre outras unidades político-administrativas - e a 'posse' - ocupação de fato mediante aldeamentos missionários católicos (Reis, 1993, p. 111-112).

Ou seja, além da expedição de títulos ou diplomas legais que conferiam um estatuto jurídico aos territórios coloniais (Estado do Brasil ou do Maranhão e Grão-Pará, capitanias reais ou donatariais, por exemplo), matéria abordada em outro estudo (Rocha, 2017), a ocupação efetiva, pela catequese daquela população preexistente - o indígena -, era imprescindível. Conforme o estudo referido, o processo de consolidação do Cabo Norte como território colonial lusitano dependia, portanto, da política imperial portuguesa no globo e do delicado equilíbrio de poder entre as potências europeias no continente e em seus respectivos impérios coloniais (Rocha, 2017). Contudo, enquanto objeto do presente artigo, eram indispensáveis, por um lado, o equilíbrio entre políticas indígenas e indigenistas (praticadas respectivamente pelas diversas nações indígenas e pelas referidas potências coloniais europeias) e, por outro, a consideração dos interesses e das ações adotadas por variados indivíduos e/ou grupos que habitavam ou percorriam as regiões próximas à foz do rio Amazonas - índios, negros, mestiços, missionários, colonos e autoridades portuguesas ou francesas, entre outros. 
Nesse sentido, durante a década de 1720, não obstante a definição do limite entre os territórios coloniais de Portugal e França naquelas partes, os agentes referidos praticaram intensos (e teoricamente proibidos) trânsito e comércio entre os dois espaços. Nossa hipótese afirma que a fronteira era um ambiente que direcionava a ação política dos homens (ela faz o homem), mas, ao mesmo tempo, constituía-se fronteira por meio dessas ações (o homem a faz). Em outras palavras, fora a circulação por aquela região que consolidara sua importância, seja para os referidos atores que a percorriam ou para as autoridades representantes dos mencionados Estados imperiais. Visando entender essa afirmação, cabe, primeiramente, apreender o que veio a ser a fronteira ou, mais especificamente, a fronteira do Cabo Norte.

\section{A fronteira colonial e o CABo Norte}

Se Frederik Turner, em escrito de fins do século XIX, tem o mérito de destacar a importância da fronteira para a formação do homem e da nação norte-americana, esta era interpretada como o avanço da 'civilização' frente ao mundo 'bárbaro' e 'selvagem' e/ou uma área caracterizada pelo espectro do isolamento e vazio demográfico (wilderness). Isto é, diferente, portanto, da fronteira europeia: uma linha ou limite existente entre nações civilizadas densamente povoadas (Turner, 2004, p. 23-27). A posição de Turner fora inovadora, pois, segundo a análise de Robert Wegner, considerava a adaptação do europeu ao ambiente ou ao modo de vida do nativo americano, para, posteriormente, valorizar a atuação do primeiro enquanto agente transformador do próprio meio (o 'legado transatlântico'). Em outras palavras, empurrando-a no decorrer do tempo, o homem é transformado pela fronteira - origem da democracia e do individualismo norte-americano - mas também a transforma - retomando a civilização após sua passagem pelo estágio primitivo. O autor destaca que a obra de Turner, não influente quando lançada, obtivera ampla aceitação a partir da década de 1920 (Wegner, 2000, p. 94-101).

Atualmente, conforme Guillaume Bocarra, antropólogos e etno-historiadores, inserindo os indígenas no centro de suas preocupações, romperam com a concepção turneriana, pois passaram a interpretar a fronteira não como "un espacio marcando un límite real entre 'civilización' y 'barbarie', sino como un territorio imaginado, inestable y permeable de circulación, compromiso y lucha de distintas índoles entre individuos y grupos de distintos orígenes" (Bocarra, 2005, §3). Outros autores destacam, ainda, a importância dos índios aliados como provedores de gêneros de subsistência e contingente guerreiro 
para a consolidação dos incipientes Estados coloniais europeus na América; bem como, inversamente, o importante papel desses Estados na concretização de poderosos grupos indígenas por meio da aliança e do acesso privilegiado ao comércio com os europeus (Whitehead, 1992, p. 130-139; Schwartz; Salomon, 1996, p. 48-52; Almeida; Ortelli, 2011, p. 2-3). Nesse sentido, segundo Neil Whitehead, "tribe' and 'state' can be seen as symbiotic social phenomena" (Whitehead, 1992, p. 136).

Sobre o Brasil colonial, segundo Wegner, se Sérgio Buarque de Holanda (em Caminhos e fronteiras) insiste em marcar diferença frente à concepção turneriana de fronteira, essa distinção remete à 'intensidade' ou ao 'grau de influência' - marcado pela lentidão das transformações, para o caso brasileiro - e não à 'natureza' das relações entre europeus e indígenas (Wegner, 2000, p. 121-123). Ou seja, da mesma forma, reitera-se a adaptação do europeu ao meio - natural ou indígena - para, em seguida, retomar o legado do primeiro pela valorização do desenvolvimento tecnológico posteriormente empreendido (Wegner, 2000, p. 140ss). De qualquer maneira, historiografia recente apresenta a aliança com os índios como uma importante estratégia de conquista e defesa por parte dos lusitanos, levando em consideração, sempre, o interesse dos primeiros nessas relações, pois usualmente envolviam trocas comerciais e/ou vantagens diversas aos indígenas - dentre outras, a defesa ou aliança militar contra seus inimigos. Isso ocorria, especialmente, em regiões pleiteadas por potências europeias concorrentes, que, não raro, disputavam intensamente a amizade dos índios, como, por exemplo, durante as investidas francesas nos primeiros anos da conquista, as guerras holandesas ocorridas no Nordeste em meados do século XVII e as demarcações - conforme os tratados de Madri, de 1750, e Santo Ildefonso, de 1777 - dos territórios coloniais de Portugal e Espanha no extremo Sul e na própria Amazônia (Garcia, 2011; Garcia, 2014; Farage, 1991).

Seja no Brasil ou na América em geral, como se verá em momento oportuno, essas relações, por um lado, possibilitaram a emergência de novos ou a reelaboração/reorganização de antigos grupos indígenas e, por outro, iluminaram a importância das missões religiosas enquanto estratégia de ocupação e posse. Nesse caso, como demonstra Tamar Herzog para os impérios coloniais de Espanha e Portugal na América, o estabelecimento de aldeamentos missionários sedentários se apresentava como elemento essencial porque a conversão transformava os índios em cristãos e, também, vassalos dos respectivos monarcas. Visto que tal conclusão era considerada "consensual and evident, they barely ever discussed or justified it” (Herzog, 2015, p. 70). Desde Nádia Farage 
(1991), literatura numerosa destaca esse fato no que se refere ao contexto dos tratados de limites assinados durante a segunda metade do século XVIII (os tratados de 1750 e 1777). A autora, cabe informar, intitulou seu estudo com as palavras de uma autoridade lusitana sobre a importância, em fins do século XVII, dos indígenas para a consolidação do território colonial português frente ao avanço missionário espanhol no rio Solimões: "Muralha dos Sertões".

Como vimos, no caso específico do Cabo Norte, a argumentação das autoridades francesas e portuguesas, durante os debates que deram origem ao mencionado tratado de 1700 , fundava-se justamente na história de ocupação efetiva daquele espaço: o 'domínio', visto que o Cabo Norte fora concedido como capitania a um conquistador português na primeira metade do século XVII, e a 'posse', expulsão dos 'hereges do norte' (ingleses e holandeses), construção de fortes e ação missionária por parte dos lusos naquele espaço durante o século XVII. Contudo, após a definição do rio Oiapoque ou Vicente Pinzon como o limite entre as partes (conforme o tratado de 1713), as fontes primárias por nós levantadas ilustram constantes trânsito e comércio além-fronteira por parte de agentes diversos, sobretudo nos anos 1720. De forma geral, nesse debate, os franceses punham dúvidas acerca da localização do Oiapoque ou Vicente Pinzon, que, conforme tais autoridades, correspondia ao rio Cachipur (ao sul da foz do Oiapoque) (Rocha, 2017, p. 537-538).

Os desacordos permaneceram, a exemplo da posição do naturalista francês Charles Marie de la Condamine nos anos 1740, que, após percorrer a Amazônia Portuguesa, considerava o Oiapoque e o Vicente Pinzon como rios distintos - este último, ao sul do Oiapoque, um braço do rio Araguari. Após agitações no início do século XIX, nas décadas de 1840 e 1850 os franceses reiteraram as dúvidas sobre o limite acordado em Utrecht. Nesse contexto, além de contra-argumentar a favor do então império do Brasil, o estudo de Joaquim Caetano da Silva reuniu as alegações dos cientistas franceses e copiosa documentação sobre a questão. Em ocasiões diferentes, os franceses reiteraram a posição de La Condamine (sobre a suposta distinção entre os referidos rios) ou localizaram o Cabo Norte na Ilha de Marajó, intentos prontamente negados por Caetano da Silva (Silva, 1861). A querela findaria somente na virada para o século XX, mediante arbítrio da Suíça, quando se consolidou de fato o território como pertencente à então República do Brasil. Atuou nos debates o Barão do Rio Branco, que, consultando o estudo de Caetano da Silva, reuniu documentos e relatos históricos sobre o caso. É curioso notar, portanto, que tanto Caetano da Silva quanto o Barão do Rio Branco praticamente ignoraram a referida circulação transfronteiriça (ocorrida na década de 1720) dos diversos 
grupos mencionados (Silva, 1861, p. 79-90; Rio Branco, 2008). O mesmo vale para Francisco Adolfo de Varnhagen, contemporâneo de Caetano da Silva, e Ciro Cardoso, já nos anos 1980 (Varnhagen, 1975, p. 21-22; Cardoso, 1984, p. 151). Por seu turno, a narrativa de Arthur Reis, publicada na década de 1940, ilustra as intensas movimentações além-fronteira por parte daqueles grupos, mas concentra esforços no sentido de destacar a atuação do Estado e das autoridades portuguesas como elemento central para a delimitação da divisa acordada (Reis, 1993, p. 129-149; Rocha, 2017, p. 532). Dentre as poucas exceções, a seguir descritas, citamos o trabalho de Flávio Gomes, limitado aos escravos negros, e o recente estudo de Wania Viana e André Pompeu.

Contudo, as informações contidas nas trocas de correspondências entre os governadores do Estado do Maranhão e Grão-Pará e Caiena e entre os primeiros e a coroa portuguesa, documentação localizada no Arquivo Público do Estado do Pará (Apep) e no Arquivo Histórico Ultramarino (AHU), bem como a atuação dos índios nos conflitos ocorridos ainda no século XVII, demonstram o reconhecido protagonismo, pelas próprias autoridades, dos transeuntes mencionados (colonos, índios, negros e mestiços, entre outros). $\mathrm{O}$ relativo silêncio encontrado nas obras brasileiras citadas, portanto, contrasta com a intensa presença desses agentes no cotidiano do mundo colonial, que, como observaremos, explicam os esforços empreendidos pelas autoridades francesas e portuguesas para angariar sua amizade. Esses, por sua vez, encontraram oportunidades - definido as suas políticas de atuação - no interior da disputa entre os impérios. Cabe informar que a natureza da bibliografia e das fontes consultadas, inevitavelmente, concede ao estudo um viés luso-brasileiro. Não obstante tal limitação, procuraremos intuir os interesses e as políticas dos demais agentes (franceses, negros e índios, entre outros).

\section{FronteIRAS FLUIDAS}

Durante a década de 1720 os governadores do Estado do Maranhão e Grão-Pará e Caiena trocaram uma série de correspondências visando sanar conflitos e estabelecer boas relações. Dentre outros, dois problemas preocupavam as autoridades: o constante desrespeito, por parte de colonos portugueses e franceses, índios e negros, do limite estabelecido entre os dois territórios coloniais pelo tratado de Utrecht (o rio Oiapoque ou Vicente Pinzon) e o comércio transfronteiriço praticado por agentes diversos. No caso dos colonos franceses, como veremos no tópico seguinte, existem muitas acusações, por parte dos governadores lusitanos, acerca da transposição da fronteira visando o trato comercial 
com alguns grupos indígenas (resgate) - especialmente os aruãs. Em relação aos colonos lusos, as referidas autoridades apresentam alguns casos.

Em 1723, uma embarcação francesa chegou ao Pará (capitania integrante do Estado) com o intuito de, segundo uma correspondência do governador de Caiena - Claude Guillouet, senhor d'Orvilliers - destinada ao governador português, comprar cavalos. Em resposta, o governador João da Maia da Gama (1722-1728) negou essa possibilidade - amparando-se no tratado de Utrecht e em leis antigas - e sugeriu que "reciprocamente entreguemos brancos e pretos que fugirem de uma para outra parte". Na ocasião, segundo o provedor da fazenda real do Pará, um sargento luso intentou vender determinados gêneros a esses franceses, que estavam embarcados na costa do Pará, especificamente no aldeamento do Maracanã (localizado entre as cidades de Belém e São Luís). Em resposta a Maia da Gama, d'Orvilliers, reconhecendo o Cabo Norte como posse lusitana, garantiu que castigaria os franceses que desrespeitassem o limite acordado, se remetidos a Caiena pelo governador português, e enviaria os lusos que costumavam trespassar essa fronteira para comerciar com os índios e coletar 'frutos'. Em tréplica, apesar de considerar falsa a acusação do francês referente aos portugueses que ultrapassavam a fronteira (ainda que, na primeira correspondência, sugerisse a troca de fugitivos), Maia da Gama concordava com os termos do acordo de permuta e, curiosamente, afirmava que mantinha preso um português chamado Manuel de Morais por dívidas contraídas com um francês. Quando descrevia o encontro ocorrido no Cabo Norte entre uma tropa portuguesa e três índios escravizados pelos franceses, considerados vassalos de D. João V pelo governador lusitano (posto que antigos habitantes de aldeamentos missionários), narrava a ação de um português chamado Pascoal de Lima, que, enquanto "mau vassalo", vendera "por engano" aos franceses um desses índios (AHU Pará, cx. 7, doc. 650).

Em 1727, os mesmos governadores tornaram a trocar correspondências e, desta vez, acusações - envolvendo invasões e atrasos mútuos na troca de fugitivos. O governador da colônia francesa afirmava que os lusitanos estavam, em terras francesas, caçando os índios palicours. Apontava, também, a existência de três portugueses habitantes de Caiena, que, conforme o texto da correspondência, deveriam retornar ao Pará por solicitação de Maia da Gama: Manuel Torres, Timóteo e Manuel Barreto. Os dois últimos, conforme a carta do francês, vendiam índios aos franceses (Timóteo estava sendo restituído ao Pará quando fugiu). Destacava-se a situação de Manuel Torres, que morava em Caiena havia 8 anos e, em função de um conflito não detalhado que o opôs ao governador e ao provedor do Estado do Grão-Pará e Maranhão, ameaçava rumar para Boston 
(Nova Inglaterra) caso o governador francês intentasse enviá-lo ao Pará (AHU Pará, cx. 10, doc. 934). Esses mesmos indivíduos são posteriormente mencionados por Maia da Gama, o que demonstra a possível credulidade do governador português acerca do caso (AHU Pará, cx. 12, doc. 1108).

Quanto à mobilidade transfronteiriça dos negros, é importante mencionar os estudos de Flávio Gomes. Procurando relativizar a concepção de mocambo ou quilombo enquanto entidade integrante de um 'mundo isolado' ou 'marginalizado', própria da historiografia clássica sobre o tema, apresenta as metáforas do 'bumerangue' e das 'cabeças de hidra' para destacar a intensa mobilidade transfronteiriça ou mesmo transatlântica, de gentes e ideias, e os contatos e cooperações entre os mais variados grupos e/ou indivíduos (escravos, taberneiros, trabalhadores assalariados, marinheiros, africanos, europeus e indígenas, entre outros) (Gomes, 1996, p. 126-128). Conforme o autor, em relação aos mocambos ou quilombos da Amazônia colonial, por sua posição geopolítica, o principal cenário era o Cabo Norte, pois, para essa região, “com a ajuda de comerciantes e grupos indígenas, negros escravos tanto do lado português quanto do lado francês migravam à procura de liberdade" (Gomes, 1996, p. 135). Nesse sentido, ainda segundo Gomes, as regiões fronteiriças constavam entre as principais localidades elegidas para o estabelecimento de mocambos, os negros dessas comunidades realizavam trocas comerciais ultrapassando as fronteiras com índios e/ou colonos europeus de nacionalidades diversas (soldados, comerciantes e lavradores, entre outros) e, por fim, o Cabo Norte era uma das áreas mais intensamente ocupadas por mocambos e negros fugitivos de toda a América Portuguesa (Gomes, 1996, p. 135-141). No que se refere às fugas de escravos negros da Amazônia Portuguesa para Caiena, embora ocorressem desde o primeiro quartel do século XVIII, foi a partir do período pombalino (segunda metade do século XVIII) que as evasões e os estabelecimentos de mocambos ou quilombos se tornaram mais intensos (Gomes, 1996, p. 135).

Conforme as fontes consultadas, a hipótese que levantamos afirma que, durante as primeiras décadas do século XVIII, as fugas de escravos negros majoritariamente partiam de Caiena em direção ao Cabo Norte ou Pará. Nesse sentido, em meio à já citada conflituosa troca de correspondências, autoridades portuguesas e francesas procuravam atrair índios e negros às suas respectivas causas. Portanto, se os portugueses procuravam vincular vassalagem aos habitantes indígenas do Cabo Norte, como observaremos adiante, os franceses argumentavam que, além de preferir o uso da mão de obra escrava negra, impedir a vinda de índios para o território francês era uma ação fora de sua 
alçada e controle. A comparação entre os tratamentos dispensados, respectivamente, a índios e negros era indispensável.

Assim sendo, o provedor da fazenda de Caiena, em carta ao governador do estado, afirmava que os franceses garantiam "a plena liberdade de todos os índios" (alguns serviam como trabalhadores livres) e "nós fazemos tão pouco caso desses índios, que eu não creio, que haja vinte em toda a colônia". Além do mais, continuava o provedor, os índios que partiam do Cabo Norte em busca de refúgio nas terras francesas - e citava os palicours (palikur) como exemplo - o faziam de livre vontade porque "nós os tratamos como forros, que se pretendem naturais, e primeiros possuidores do país, vão e tornam conforme o seu desejo". Argumentação semelhante recuperava o governador de Caiena, também em correspondência com a autoridade respectiva do Estado, sobre os muitos palicours, aruãs e maraunos ${ }^{3}$ que rumaram para o lado francês: "se as nações livres de pleno direito passassem de seu moto próprio e vontade de um domínio a outro, se não saberia com justiça os ir inquietar”. Por fim, alegava que proibira em Caiena a venda de escravos índios transportados do Pará, apesar de "estimarem [os colonos franceses] mais um negro do que dez desses brutos [escravos índios]" (Apep, Cód. 7, doc. s. n).

Ora, é claro que, nesse contexto de acusações mútuas, o governador francês parecia querer minimizar as supostas investidas dos colonos de Caiena sobre os índios (considerados vassalos portugueses ou não) que habitavam o território luso e louvar o tratamento francês dispensado aos indígenas diante das práticas dos lusitanos em relação a eles. Contudo, as fontes lusitanas, por vezes, confirmam as dificuldades envoltas ao usufruto da força de trabalho indígena livre em terras portuguesas. Assim, se no início do século XVIII ocorreram conflitos envolvendo os aldeamentos da Ilha de Joanes (Marajó), no que se refere à recusa (fugas) dos aruãs em servir como remadores, às violências sofridas nesses serviços, ao ataque executado por esses índios contra os missionários franciscanos, à breve proibição (posteriormente revogada) de utilizar os mesmos aruãs como mão de obra e a presença comercial francesa constante e ameaçadora nessa conjuntura (Livro Grosso..., 1948a, p. 228-230 e 247-248, 260 e 287; Livro Grosso..., 1948b, p. 14, 93, 100, 115 e 131), em carta ao rei de 1727 o governador do estado João da Maia da Gama recuperava a comparação entre os tratamentos francês e português destinados aos índios livres das respectivas colônias. Nesse sentido, descrevendo a fortaleza francesa recentemente erigida nas proximidades da fronteira (ainda que em território de Caiena), a centena de soldados franceses e os cindo aldeamentos instalados na região com índios e principais bem armados e vestidos ("com seus bastões com as 
armas d'El Rey de França”), afirmava que os indígenas reconhecidos como franceses "não trabalhavam". Em outras palavras, preocupava-se com "o diferente trato que os franceses dão a estes índios daquele que nós damos aos nossos", isto é, os primeiros vestiam ("com aquela grandeza e com tanta despesa") e não exigiam o trabalho dos segundos, ao passo que os portugueses os obrigavam "como cativos, a remar de dia, e de noite um mês para lhe pagarmos com duas varas de algodão; os franceses armando-os, e fazendo-os soldados, e nós unicamente fazendo-os remeiros para o nosso serviço". Reconhecia que se tratava de uma estratégia francesa "para os adquirir e agregar"; o que escapava aos portugueses, "sem se atender ao futuro e às defensas do Estado, matéria digna de se fazer nela toda a ponderação" (AHU Pará, cx. 10, doc. 934).

Porém, quando o governador João da Maia da Gama propôs a permuta de transeuntes já referida, as notícias sobre as fugas de escravos negros de Caiena para o lado lusitano passaram a se multiplicar. Um deles, vale informar, saindo do Pará atravessou o Atlântico e alcançou a ilha de Cabo Verde, enquanto outro, sem licença do governador e com a ajuda de um capitão português, chegou a Lisboa (AHU Pará, cx. 7, doc. 650). Cabe destacar também o uso político da fronteira e do conflito entre portugueses e franceses por parte dos escravos negros fugitivos de Caiena, quando, por exemplo, alguns desses chegaram ao Pará afirmando que os franceses estavam construindo uma fortaleza em território português no Cabo Norte - afirmação posteriormente desmentida pelos índios da região, pois a fortaleza em questão foi erigida em território francês (ainda que próximo à fronteira); ou quando alguns escravos negros, também fugidos da colônia francesa, obtiveram a permissão do monarca português para permanecer no Pará. Sobre um desses casos, no qual um negro ou mestiço (José, também referido como um "mameluco amulatado") havia matado membros da família do seu senhor (incluindo o próprio) e chegado ao Pará, as autoridades francesas (o governador e o provedor da fazenda de Caiena) argumentavam que o direito de asilo só era válido aos livres - caso dos índios que rumavam do lado português para o francês - e não aos culpados por crimes (AHU Pará, cx. 12, doc. 1108; e Apep, cód. 7, doc. s/n). Ora, de fato, em carta régia de 1732 enviada ao governador Alexandre de Sousa Freire (1728-1732), o monarca português ordenava expressamente: "constatando-vos que restituindo-os escravos se lhes há [os franceses] de impor a pena de morte os não deveis restituir, pois se vieram valer da minha real proteção" (Livro Grosso..., 1984b, p. 255; e AHU Pará, cx. 11, doc. 1040).

Em síntese, observamos que as autoridades francesas encaravam com naturalidade o pleno trânsito dos indígenas enquanto característica elementar de 
sua liberdade e 'naturalidade' na região - e o diziam expressamente aos lusitanos. Entretanto, o mesmo não era cabível aos negros, posto que escravos e em determinado caso um criminoso. Nas páginas que se seguem, demonstraremos que a posição dos portugueses possuía semelhanças e diferenças: por um lado, como já informado, uma vez assinado o tratado de 1713 investiram esforços no sentido de interpretar os habitantes do Cabo Norte como vassalos lusos, que, portanto, deveriam obedecer às proibições de trânsito e comércio inscritas no acordo; por outro, em relação àqueles que rumavam para Caiena (definitivamente ou não), consideravam alguns criminosos dentre esses mesmos habitantes, em especial, certos aruãs.

\section{Os ARUÃs OU A POLÍtiCA INDÍGENA NO CABo Norte}

Consideramos que a fronteira entre Caiena e o Pará representava a condição primordial para a consecução da política adotada por indivíduos ou grupos aruãs que habitavam o Cabo Norte e arredores, região que Curt Nimuendajú, com algumas das diversas ilhas - dentre elas a Ilha de Joanes e Caviana - e regiões continentais do Pará, considera área de residência e atuação dessa nação desde o século XVII (Nimuendajú, 1948, p. 195). Em outras palavras, o encontro entre as duas potências coloniais possibilitava a prática de um interesse caro a esses índios: o comércio ou a troca de cativos índios por produtos europeus (resgates). Nesse sentido, como observaremos, tais aruãs, em alguns casos considerados vassalos portugueses pelas autoridades lusitanas, costumavam capturar índios aldeados em missões lusas (isto é, também entendidos como súditos portugueses) e rumavam para Caiena no intento de vendê-los. Portanto, nossa hipótese afirma que o ambiente fronteiriço representava a situação ideal ou mesmo a condição capital para a execução da política adotada por aqueles aruãs, pois, por um lado, conjugava 'escravos' (índios aldeados pelos portugueses) e seus compradores (colonos de Caiena) em espaços relativamente próximos e, por outro, comportava um terreno de difícil acesso - alagadiço e marcado pelo fenômeno da pororoca - que possibilitava independência, e por isso mobilidade, por parte de seus habitantes. Em outras palavras, se os poucos estudos que mencionam os aruãs os interpretam como privilegiados aliados dos franceses (Whitehead, 1992, p. 137 e 138) ou sob o prisma da negação da fronteira político-administrativa estabelecida pelos europeus (seja simplesmente não respeitando o limite acordado ou possuindo uma noção particular e pré-colonial de fronteira) (Viana; Pompeu, 2015, p. 109-115), acreditamos que aquele limite definido pelos Estados 
europeus era elemento essencial para a execução das políticas então adotadas por esses índios.

Nesse sentido, historiografia recente sobre a América Espanhola colonial, reavaliando a dicotomia turneriana civilização/barbárie e adotando uma imagem da fronteira enquanto espaço de intensa movimentação por parte de indivíduos e grupos sociais, destaca as representações, as classificações e/ou os etnônimos atribuídos pelos agentes coloniais aos diversos grupos indígenas, muitas vezes em conformidade com as intrincadas tramas entre políticas indigenistas ou imperiais e políticas indígenas executadas usualmente em áreas fronteiriças. Exemplos clássicos são os nomes étnicos adotados - criados ou ressignificados - e sua relação com as dicotomias atribuídas aos diversos grupos indígenas, como, por exemplo, bárbaros ou selvagens/mansos, inimigos/amigos, habitantes das montanhas/habitantes das planícies e sedentários/errantes, entre outras. Essas nomeações, classificações e/ou qualificações, por vezes, eram incorporadas pelos próprios índios, processo que, não raro, permitia a reelaboração de culturas, etnias e/ou identidades. Tratava-se de uma forma de organizar o mundo nativo-americano reduzindo e/ou amalgamando a imensa e complexa multiplicidade de culturas, etnias e redes de relacionamentos - guerras, alianças e negociações (Whitehead, 1992; Schwartz; Salomon, 1996, p. 443-456; Bocarra, 2005; Almeida; Ortelli, 2011). Segundo Bocarra, essa organização do mundo americano, executada pela empresa colonial, influenciou as diversas historiografias nacionais e nelas perdurou, pois "parte de los estudios etnohistóricos relativos a las zonas fronterizas hayan retomado representaciones coloniales bastante discutibles"; e "se adoptaron ciertas categorías de la época colonial de modo acrítico" (Bocarra, 2005, \$ 26 e 27).

Sobre o Brasil colonial, durante as primeiras décadas da conquista, as nomeações classificatórias e qualificativas também estiveram presentes. Dentre muitos outros exemplos, destacam-se os nomes relacionais (alguns pares opostos), inteligíveis no contexto da conquista ou colonização, que usualmente uniam ou cingiam grupos indígenas - tupi/tapuia, tamoio/temiminó, potiguaras e tabajaras, entre outros (Monteiro, 2001, p. 17-24 e 65-70; Almeida, 2003, p. 47-49 e 62-65). Ora, a mesma historiografia informa que as dicotomias estagnadas supracitadas (amigos/inimigos e mansos/bárbaros ou selvagens, entre outras), por vezes, não correspondiam às diferentes políticas adotadas por europeus e indígenas durante as transformações conjunturais usualmente ocorridas, isto é, as alianças/inimizades e as nomeações/classificações/qualificações não eram estanques, mas cambiavam conforme as avaliações, efetuadas 
por europeus ou indígenas, das situações, momentos e/ou eventos históricos (Monteiro, 2001, p. 65-70; Garcia, 2011, p. 2-8; Garcia, 2014, p. 332-340). Nesse sentido, dada a complexidade das oscilantes relações explanadas, Eduardo Viveiros de Castro afirma que a atribuição de etnônimos estanques era "fruto de uma incompreensão total da dinâmica étnica e política do socius ameríndio", distante, portanto, da "natureza relativa e relacional das categorias étnicas, políticas e sociais indígenas" (apud Monteiro, 2001, p. 57). A esse comportamento oscilante, aliás, os lusitanos atribuíam um termo específico (a princípio vinculado à religião, mas não só): a 'inconstância' .

Quanto aos aruãs, passaram a constar de forma recorrente na documentação portuguesa durante a segunda metade do século XVII. Em 1643, quando uma embarcação portuguesa naufragou na Ilha de Joanes e parte de sua tripulação foi massacrada em sacrifício antropofágico pelos índios da região, os aruãs foram descritos com base na imagem do bárbaro selvagem canibal. Nesses anos, ao que parece, integrantes dessa nação indígena por vezes eram referidos pelas fontes portuguesas somente como 'selvagens', quando, pouco depois, os jesuítas Antônio Vieira (nos anos 1650) e João Felipe Bettendorff (esse em fins do século XVII) identificaram os aruãs entre os nheegaíbas. Assim sendo, Vieira e Bettendorf afirmavam que essa nação, com outras seis, integrava os nheengaíbas, que, vale informar, significava em língua geral (derivada do tupi) má língua ou língua incompreensível (nheengaíbas e aruãs pertenciam ao tronco linguístico aruaque). Tendo em mente o reconhecimento da indispensável aliança com os indígenas pelas autoridades portuguesas, por meio do trato comercial, os lusos disputaram com os holandeses a amizade dos nheengaíbas em meados do século XVII e com os franceses a dos aruãs em fins da mesma centúria. No caso dos últimos, nos anos 1690 integrantes dessa nação auxiliaram os franceses na destruição de dois fortes lusitanos instalados no Cabo Norte (construídos nos anos 1680), apesar dos descimentos de aruãs constantemente realizados por missionários portugueses desde a década de 1660 enquanto estratégia declarada de posse territorial (Rocha, 2018). Após o tratado de Utrecht e durante a década de 1720, um novo termo classificatório, atribuído pelos lusos, passou a acompanhar alguns aruãs: o 'rebelde'.

Conforme Rosário Villari, no século XVII o rebelde era o vassalo traidor que, se em outros períodos possuía alguma aceitação ou mesmo exaltação (enquanto ideal de resistência à opressão ou tirania), passou a carregar forte condenação e descrédito na teoria política europeia: era o executor de uma mudança política, qualquer forma de protesto ou insubordinação, mas, 
também, “criminosos, bandidos, perversores de toda a espécie que pouco ou nada tinham a ver com a subversão política ou heresia" (Villari, 1995, p. 99). O dicionário português elaborado por Raphael Bluteau no século XVIII, dentre outros significados, apresentava o rebelde como aquele que "fez ou entrou em rebelião". O termo rebelião, por sua vez, era interpretado como "levantamento dos vassalos contra o seu soberano". Por fim, ainda segundo Bluteau, rebelar-se significava "faltar na fé e obediência devida ao seu soberano" ou "rebelar-se à razão, não querer seguir os seus ditames". Este último, enfim, parecia estar relacionado ao adjetivo "rebelão", isto é, "que não obedece à razão, obstinado, que faz o contrário do que deve por teima" (Bluteau, 1789, p. 291).

De fato, um aruã constantemente referido nas fontes portuguesas durante a década de 1720, o índio Guaimá, era assim apresentado pelo sargento Antônio Freire de Mendonça em um auto de testemunhas: andavam "os ditos franceses resgatando índios, e o mais que achavam e amparavam, e favoreciam ao rebelde Guaymá cabeça do gentio aruã, o qual gentio sendo dos domínios desta coroa, como o dito o é, tem assaltado por vezes as aldeias junto a esta cidade [Belém]". No mesmo auto, outro sargento garantia que o referido índio "têm incitado ao dito gentio aruã a faltar à obediência de Sua Majestade, e assaltar as aldeias" (Reis, 1993, p. 217-218). Nas páginas que se seguem, procuraremos mostrar que, do ponto de vista dos portugueses, o vínculo entre o termo 'rebelde' - preferível a 'inconstante' - e os aruãs estavam intimamente relacionados à definição da fronteira, região de difícil acesso aos europeus e, por isso mesmo, de intensa mobilidade e liberdade para esses indígenas. Parece que, uma vez habitante do território recentemente reconhecido como porção lusitana (por Portugal e França), a classificação portuguesa intentava marcá-los como vassalos, mesmo que gentios, traidores, criminosos ou faltos de razão. Em outras palavras, conforme a visão dos portugueses, aquele reconhecimento conferia vassalagem aos habitantes do território ("sendo dos domínios desta coroa, como o dito o é”, destacava o sargento Mendonça sobre Guaimá). Possivelmente, tratava-se de uma resposta à posição francesa já citada, segundo a qual a vinda dos aruãs e outros índios às terras francesas era uma ação fora de sua alçada e controle ("vão e tornam conforme o seu desejo" e "nações livres de pleno direito" que passavam "de seu moto próprio e vontade de um domínio a outro"). O caso de Guaimá é significativo, pois, como se verá, as fontes portuguesas encontradas não informam sua origem (se era aldeado ou não), mas o epíteto que lhe era atribuído (rebelde) parecia incluí-lo entre os vassalos de S. Majestade. 
O auto de testemunhas supracitado resultou da incursão da tropa guarda-costa comandada pelo capitão João Paes do Amaral, que objetivava (conforme o seu regimento) vigiar a costa do Cabo Norte, guerrear os aruãs - em função do constante comércio/resgate realizado em terras lusas entre esses índios e os franceses - e procurar um antigo marco quinhentista (atestando a existência prévia do limite) supostamente estabelecido nas proximidades do rio Oiapoque. O auto, de 1723, constava em anexo a uma carta do governador João da Maia da Gama ao rei (resumindo o averiguado no auto) e contava com os testemunhos do capitão Paes do Amaral, de dois sargentos, cinco soldados e, por fim, de dois índios. Essas testemunhas atestaram a suposta existência do marco, relataram o encontro com três índios (Antônio, José e Felipe) fugitivos de uma tropa invasora de resgate francesa (dois deles apresentaram seus depoimentos no auto em questão) e descreviam a estratégia de penetração dos estrangeiros. De forma geral, os franceses ultrapassavam a fronteira e, "passando de aldeia em aldeia pelos índios seus compadres”, percorriam a região efetuando resgates e razias, por vezes contra aldeamentos portugueses, sobretudo com o auxílio de Guaimá e outros aruãs - que, garantia uma testemunha, habitavam "toda a costa até o Cabo Norte e vizinhanças de Caiena". Segundo os depoentes, um dos assaltos efetuados pelo grupo de Guaimá - índios usualmente "favorecidos" e "ocultados" pelos franceses após essas razias - foi direcionado contra o aldeamento de Moribira, próximo a Belém, ocasião na qual o próprio Guaimá, conforme o testemunho de Paes do Amaral, incitou os demais aruãs "a faltarem a obediência à S. Maj.". Conforme os depoimentos dos dois índios mencionados, Antônio e José, o próprio Guaimá em pessoa vendia índios em Caiena. Cabe informar que ambos eram testemunhas oculares, pois, antes de escaparem da tropa de resgate referida (integrada por dois franceses, dois índios da própria tropa guarda-costa portuguesa, Guaimá e outros aruãs) e encontrar a tropa de Paes do Amaral, o primeiro vivia há 4 anos e o segundo há 3 na colônia francesa (Reis, 1993, p. 213-225). Este último, aliás, teria sido vendido pelo próprio Guaimá em Caiena. Conforme Antônio essa era uma prática recorrente, além de informar que o "rebelde" realizava as vendas em troca de pólvora, bala e armas. Parecia exagerar ao afirmar que, em relação aos índios que com os franceses cometiam assaltos em território português, "todos os índios que tem a colônia de Caiena são dos distritos de Portugal e essas poucas de aldeias que tem o mesmo distrito de Caiena são compostas todas de índios nossos" (Reis, 1993, p. 224). 
Percebe-se, conforme o testemunho, que nem todos os índios 'levados' pelos franceses eram escravizados, mas, também, postos em aldeamentos missionários. Em correspondência enviada ao governador de Caiena em 1723, além de abordar os assuntos averiguados no auto citado (existência do marco e comércio/ resgate francês além-fronteira) e negociar a troca de fugitivos, Maia da Gama afirmava que entre os franceses encontrados praticando resgates no Cabo Norte, localizados pela tropa de Paes do Amaral, constava o "rebelde Guaimá", que, garantia, “escapou à minha tropa”. Maia da Gama, reproduzindo parte do testemunho do índio Antônio, solicitava ao governador de Caiena que "não favoreça a este [Guaimá], nem aos mais rebeldes aruãs, a quem os súditos de V.S. estão fornecendo de pólvoras, e balas, e acoitando-os para não serem castigados". Ainda segundo Maia da Gama, os três índios que fugiram da tropa francesa invasora ao encontro da tropa portuguesa não poderiam ser restituídos - bem como outros de mesma condição vendidos pelos "rebeldes aruãs" (embora seus 'donos' franceses devessem ser ressarcidos) - porque eram aldeados/vassalos portugueses, isto é, livres. Dois deles (José e Felipe), informava o governador, foram vendidos aos franceses pelo próprio "rebelde Goaimar cabeça dos aruãs" (AHU Pará, cx. 7, doc. 648; e AHU Pará, cx. 10, doc. 934).

Em carta do mesmo ano (1723) ao rei, o governador português afirmava que os franceses não respeitavam o Tratado de Utrecht, pois “praticavam todos os índios daquela parte e reduzidos se não à sua obediência à sua amizade trato e comércio" sem que a tropa guarda-costa pudesse perceber em função da impossibilidade de vigilância do rio Oiapoque - não ultrapassavam o Macapá (localização de um antigo seiscentista), a meia distância do Oiapoque. Tal limitação permitia a comunicação dos franceses com os aruãs, visto que "com eles se achavam seu principal, o rebelde Guaimá” (AHU Pará, cx. 10, doc. 934). Em carta ao rei de 1722, o governador Maia da Gama já descrevia a dificuldade em manter a vigilância do Cabo Norte por parte da tropa guarda-costa - atuante somente entre janeiro e abril, permanecendo a região desguarnecida durante o restante do ano -, informava que o assalto dos aruãs a Moribira resultou na captura de 26 "índios nossos entre machos e fêmeas" e, portanto, sugeria a ereção de um forte na boca do rio Oiapoque (AHU Pará, cx. 10, doc. 934).

A opção por uma guerra aberta contra os aruãs foi, por parte dos lusitanos, um tanto vacilante. Os regimentos (4) concedidos aos cabos das tropas guarda-costa expedidos nos anos de 1727 e 1728, respectivamente Francisco de Melo Palheta e Manuel Maciel Parente, descreviam a união entre Guaimá e os mexianas durante os ataques a tupinambás vassalos portugueses e ao 
aldeamento de Arnapijó (localizado na região continental do Pará, próximo à foz do rio Amazonas) - donde levaram muitas índias e mataram muitos índios. Em relação a um dos regimentos de 1727, visto que uma devassa de 1723 confirmara o assalto que Guaimá e os aruãs realizaram a Arnapijó, dever-se-ia atacar somente os responsáveis pelo delito e não qualquer aruã, pois estes últimos seriam "chamados à paz e tratados com afabilidade" - alguns desses, aliás, preparavam-se para descer a aldeamentos portugueses quando foram atacados por Guaimá. Outro regimento do mesmo ano informava que o referido Guaimá vendia índios vassalos lusos não só aos franceses de Caiena, mas também aos holandeses do Suriname, além de afirmar que um "moço" de Belém naufragou na área de atuação do índio, "donde o comerão" (Reis, 1993, p. 207 e 212).

Os regimentos de 1728 apresentavam uma reviravolta no caso: atestavam a morte de Guaimá por motivo não revelado; descreviam o sucesso referente à paz, estabelecida no ano anterior, por meio das ações de franciscanos, com os aruãs e mexianas da região do Macapá - com os quais pretendia-se estabelecer um arraial/presídio para impedir o comércio francês (Reis, 1993, p. 209210 e 235-236); e, por fim, ordenavam a desistência da guerra, visto que "não convém na conjunção presente", em favor da missionação e do descimento daqueles aruãs e seus parentes - a quem, garantia um dos regimentos, "os ajudaremos, defenderemos e guardaremos" (Reis, 1993, p. 209). Em carta do mesmo período ao governador de Caiena, Maia da Gama mencionava a morte de Guaimá e acusava: "mas é sem dúvida que nesta colônia foi admitido, e praticado, bem tratado, e socorrido, e por ele foram praticados muitos índios, e nações, que para lá tem ido contra o tratado de Utrecht” (AHU Pará, cx. 12, doc. 1108).

De forma geral, esses mesmos regimentos explicitavam claramente a ameaça representada pelas relações comerciais entre franceses e demais aruãs, inclusive daqueles que, na condição de aldeados, eram considerados vassalos portugueses. Isto é, como informamos, também os índios livres eram atraídos pelos franceses, práticas que geravam verdadeiras disputas pela amizade dos indígenas. Nesse sentido, os regimentos destacavam a atração exercida pelos franceses dos aruãs e araris que foram transferidos pelos lusos da Ilha de Joanes ao rio Araguari (Cabo Norte), ação justificada por uma epidemia de bexigas, a serem 'praticados' por um franciscano português acompanhado por dois principais - um marauno do aldeamento de Mortigura (localizado no rio Guamá, muito próximo a Belém), que posteriormente desceu parentes então 
unidos aos transferidos, e um principal do aldeamento do Igarapé Grande da Ilha de Joanes; ordenavam a inspeção, por parte de um franciscano português, dos "rebeldes aruás" e "seus cunhamemas associados" (colonos casados com índias) estabelecidos próximo à região do Macapá; preceituavam a vistoria de canoas que transitassem com 'peças' sem licença para tal; dispunham sobre a prisão do principal Gonçalo, que, após ser degredado para o Maranhão por comerciar (resgates) com franceses, retornara ao Cabo Norte sem as licenças devidas com alguns aruãs (ao que parece, vassalos portugueses) (Reis, 1993, p. 207-210 e 226-238).

Esses documentos também descreviam as constantes fugas ao Cabo Norte, visando evitar o batismo de seus respectivos filhos, praticadas por índios dos aldeamentos de Arucará e Aricuru (ambos localizados no Pará, ao sul da Ilha de Joanes); solicitavam a captura dos irmãos aruãs Belquior e Bernardo, que, provavelmente, influenciaram tais fugas e também as deserções de índias nheengaíbas que habitavam essas povoações, pois costumavam aportar com licenças do governador em ambos os aldeamentos e posteriormente rumavam para Caiena visando o negócio dos resgates, "usando mal a nossa amizade e a obediência à vassalagem” (Reis, 1993, p. 233); por fim, dentre outras questões, ordenavam aos cabos das tropas que "praticassem" todos os índios encontrados, garantindo a eles ajuda e defesa contra os seus inimigos e "contentando-os com qualquer coisa que levar da fazenda real” (Reis, 1993, p. 229). Cabe informar que todos os aldeamentos mencionados (Moribira, Arnapijó, Mortigura, Igarapé Grande, Arucará e Aricuru) se destacam pela longevidade de sua existência, pois todos foram fundados entre o século XVII e início do XVIII, e pela proximidade à Ilha de Joanes (circulando-a) e Belém. Ou seja, na medida do possível, eram aldeamentos antigos e sedentários.

Enfim, se a origem de Guaimá não está clara, quanto à sua condição de índio aldeado ou não, o fato é que indígenas como Gonçalo, Belchior e Bernardo eram, ao que tudo indica, considerados vassalos missionados/aldeados pelos portugueses. Aliás, se os lusitanos pensaram que com a morte de Guaimá a rebeldia aruã poderia cessar, João da Maia da Gama, em carta ao rei de 1729, apresentava um novo líder aruã rebelde: Jaraú, que, antigo morador de um aldeamento português da ilha de Caviana (localizada entre o Cabo Norte e a Ilha de Joanes), possuía patente concedida pelo governador anterior e praticava razias contra aldeamentos lusos no intuito de obter cativos para comerciar com os franceses (AHU Pará, cx. 12, doc. 1108). Por fim, ao que parece, as alianças estabelecidas pelos aruãs não se restringiam aos franceses 
ou portugueses. Nesse sentido, existem menções, conforme Maia da Gama, a aruãs vendendo gêneros (peixe-boi) a um grupo integrado por um mulato, um clérigo, uma mulher casada e cinco índios forros; em outra ocasião, o novo governador francês, Marschalk de Charanville, descrevia o transporte de escravos negros que fugiram de Caiena ao Pará em canoas aruãs (AHU Pará, cx. 12, doc. 1108; e Apep, cód. 7, doc. s. n.).

\section{CONSIDERAÇÕES FINAIS}

Acreditamos que a fronteira deve ser observada em escalas micro e global. No caso desta última, a historiografia brasileira destaca a importância do tratado de 1713 para sanar conflitos envolvendo as potências coloniais europeias no continente, apesar de considerara a Amazônia uma área de colonização periférica ou marginal (Rocha, 2017), mas o silêncio predomina em relação às agitações regionais ocorridas na década de 1720 - no que se refere aos acontecimentos propriamente ditos ou ao protagonismo de negros e índios. Reduzindo a observação à escala local, consideramos que a fronteira direcionava a ação política dos mais variados grupos e os conectava ao globo (lembremos dos negros que atravessaram o Atlântico e do português que ameaçava rumar para Boston). Nesse sentido, segundo as fontes lusas, durante a década de 1720, portugueses comerciavam em Caiena, franceses capturavam indígenas no Cabo Norte, escravos negros rumavam do lado francês para o português, índios partiam do Cabo Norte para Caiena. Quanto aos aruãs, circulavam intensamente por ambos os espaços, mantinham relações (inclusive comerciais) com os mais variados indivíduos ou grupos e permitiam sua mobilidade naquela região de difícil acesso. Visto que, para os Estados europeus, a missão religiosa confirmava a posse da região, franceses e portugueses pareciam disputar (desde o século XVII) a amizade desses índios. Se alguns aruãs, que agora habitavam terras lusas (conforme o tratado de Utrecht) ou 'civilizadas' (no dizer eurocêntrico de Turner), foram interpretados pelos portugueses como vassalos rebeldes/criminosos, essa condição permitia a conexão, pela fronteira, entre cativos e compradores. Em síntese, a fronteira - central - foi condicionada pela política aruã e a condicionou. 


\section{FONTES}

Livro Grosso do Maranhão. Anais da Biblioteca Nacional do Rio de Janeiro (ABNRJ), v. 66(a) e 67(b), 1948a e 1948b.

Arquivo Público do Estado do Pará (Apep), códice 7.

Arquivo Histórico Ultramarino de Lisboa. Avulsos do Pará (AHU Pará).

\section{REFERÊNCIAS}

ALMEIDA, Maria Regina C. de. Metamorfoses indígenas: identidade e cultura nas aldeias coloniais do Rio de Janeiro. Rio de Janeiro: Arquivo Nacional, 2003.

ALMEIDA, Maria Regina C. de; ORTELLI, Sara. Atravesando fronteras: circulación de población en los márgenes ibero-americanos. Siglos XVI-XIX. Nuevo Mundo Mundos Nuevos, Debates, p. 1-6, 2011.

BLUTEAU, Raphael. Dicionário da Língua Portuguesa. Lisboa: Oficina de Simão Tadeu Ferreira, 1789.

BOCARRA, Guillaume. Mundos nuevos en las fronteras del Nuevo Mundo. Nuevo Mundo Mundos Nuevos, Debates, p. 1-39, 2005.

CARDOSO, Ciro. Economia e sociedade em áreas coloniais periféricas. Guiana Francesa e Pará (1750-1817). Rio de Janeiro: Graal, 1984.

FARAGE, Nádia. As muralhas dos sertões: os povos indígenas do rio Branco e a colonização. Rio de Janeiro: Paz e Terra: Anpocs, 1991.

GARCIA, Elisa. "Ser índio" na fronteira, limites e possibilidades. Rio da Prata, c.17501800. Nuevo Mundo Mundos Nuevos, Debates, p. 1-13, 2011.

GARCIA, Elisa. Trocas, guerras e alianças na formação da sociedade colonial. In: FRAGOSO, João; GOUVÊA, Maria de Fátima. O Brasil colonial, 1443-1580. v. 1. Rio de Janeiro: Civilização Brasileira, 2014.

GOMES, Flávio dos Santos. Nas fronteiras da liberdade. Anais do Arquivo Público do Pará, Belém: Apep, v. 2, t. 1, p. 125-152, 1996.

HERZOG, Tamar. Frontiers of Possession: Spain and Portugal in Europe and the Americas. Cambridge: Harvard University Press, 2015.

MONTEIRO, John. Tupis, tapuias e historiadores: estudos de História Indígena e do indigenismo. 2001. Tese (Livre Docência) - Departamento de Antropologia, Universidade Estadual de Campinas (Unicamp). Campinas, 2001.

NIMUENDAJÚ, Kurt. The Turiwara and Aruã. In: STEWARD, Julian (coord.). Handbook of South American Indians. v. 3. Washington, DC: Smithsonian Institution, 1948.

REIS, Arthur Cézar F. Limites e demarcações na Amazônia brasileira: a fronteira colonial com a Guiana Francesa. v. 1. Belém: Secult, 1993. 
RIO BRANCO, Barão do. Questões de limites: Guiana Francesa. Brasília: Senado Federal, 2008.

RIVET, Paul; REINBURG, Pierre. Les indiens Marawan. Journal de Société des Americanistes, Paris, v. 13, p. 103-118, 1921.

ROCHA, Rafael Ale. Os aruã: políticas indígenas e políticas indigenistas na Amazônia Portuguesa. Revista Brasileira de História e Ciências Sociais, Porto Alegre: UFRG, v. 10, n. 19, p. 72-93, 2018.

ROCHA, Rafael Ale. 'Domínio' e 'Posse': as fronteiras coloniais de Portugal e França no Cabo Norte. Tempo, Niterói: UFF, v. 23, n. 3, p. 529-545, 2017.

SCHWARTZ, Stuart; SALOMON, Frank. New Peoples and New Kind of People. In: SCHWARTZ, Stuart; SALOMON, Frank (org.). The Cambridge History of the Natives Peoples of America. v. III, 2nd part. Cambridge: Cambridge University Press, 1996.

SILVA, Joaquim Caetano da. L'Oyapoc et l'Amazone: question brésilienne et française. 2 v. Paris: L. Martinet, 1861.

TURNER, Frederik J. O significado da fronteira na história americana. In: KNAUSS, Paulo (org.). Oeste Americano. Niterói: Eduff, 2004.

VARNHAGEN, Francisco Adolfo de. História Geral do Brasil: Antes da sua separação e independência de Portugal. v. 4. São Paulo: Melhoramentos, 1975.

VIANA, Wania; POMPEU, André. Ao longo do sertão: guerra, fronteira e espaço indígena na Amazônia colonial. Estudos Amazônicos, Belém: UFPA, v. 13, n. 1, p. 99-133, 2015. Disponível em: https://pib.socioambiental.org/pt/ Povo:Palikur\#Fontes_de_informa.C3.A7.C3.A3o.

VILLARI, Rosário. O Rebelde. In: VILLARI, Rosário (coord.). O homem barroco. Lisboa: Presença, 1995.

WEGNER, Robert. A conquista do Oeste: a fronteira na obra de Sérgio Buarque de Holanda. Belo Horizonte: Ed. UFMG, 2000.

WHITEHEAD, Neil. Tribe Make States and a States Make Tribes. In: FERGUSON, Brian; WHITEHEAD, Neil. War in Tribal Zone. Santa Fe, NM: School of American Research Press, 1992.

\section{NOTAS}

${ }^{1}$ A pesquisa conta com apoio financeiro da Universidade do Estado do Amazonas (UEA) e do Conselho Nacional de Desenvolvimento Científico e Tecnológico (CNPq). Agradeço a Bruno Aranha, Gefferson Rodrigues e José Eudes Gomes.

${ }^{2}$ Utilizaremos esse termo para designar o trânsito que, especificamente, ultrapassava a linha definida pelo Tratado de Utretch (1713).

${ }^{3}$ Os maraunos são, possivelmente, os marawan ou maruan descritos por Rivet e Reinburg. 
Segundo os autores, também são chamados de palikour okawan e rukuan - ou, ainda, maraouanes ou maraones, conforme certa fonte francesa - e habitavam a margem esquerda do rio Oiapoque e o leste do mesmo rio (ao redor do Cabo Orange, localizado na foz do mesmo Oiapoque). Foram aldeados com os Tocojennes e os Maourioux pelo padre Joseph d'Ansillac (RIVET; REINBURG, 1921, p. 103-104). Os primeiros registros sobre os palikur, que os localizavam na costa logo acima da foz do rio Amazonas (no Cabo Norte/Amapá), são datados do início do século XVI. A migração em direção a Caiena teria começado em meados do século XVII, tornando-se intensa durante a primeira metade do setecentos em razão das pressões e violências dos portugueses (https://pib.socioambiental.org/pt/ Povo:Palikur\#Fontes_de_informa.C3.A7.C3.A3o).

Artigo recebido em 18 de janeiro de 2019.

Aprovado em 10 de julho de 2019.

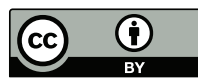

